\title{
Study of Variations in Heart Rate., QT and QTe During Different Phases of Menstrual Cycle
}

\author{
Gidugupati Anuradha ${ }^{1}$, Mudassir Mirza² \\ ${ }^{1}$ Assistant Professor of Physiology, Gandhi Medical College, Secunderabad, T.S., \\ ${ }^{2}$ Assistant Professor of Physiology, Osmainia Medical college, Koti, Hyderabad, T.S.
}

\begin{abstract}
Aim: The present study was undertaken with the aim to investigate influence of hormonal fluctuation during menstrual cycle on ECG.

Materials and Method: The present study was carried out on 30 healthy female medical students in the age group of 18 to 23 years with normal menstrual cycle of 27-33 days. ECG was recorded on $2^{\text {nd }}, 11^{\text {th }}, 22^{\text {nd }}$ day of menstrual cycle (corresponding with menstrual phase, proliferative phase and secretory phase of menstrual cycle), using AD INSTRUMENT-POWERLABß/30 Series.

Results: The study revealed that Heart rate was significantly $(\mathrm{P}<0.05)$ increased in secretory phase (98.26 \pm 10.44$)$ compared to menstrual phase $(91.85 \pm 10.27)$.QT and QTc interval showed increase during proliferative phase but not significant.

Discussion: Fluctuation in both estrogen and progesterone during menstrual cycle influence not only phaseII of cardiac action potential but also autonomic tone which could have led to prolonged QTc in Proliferative phase and increase in heart rate during secretory phase in present study, which provides a screening tool to avoid morbidity due to intake of drugs which prolonged QTc interval during menstrual cycle. But QTc interval in present study was not increased significantly as it was done during single cycle.
\end{abstract}

Keywords: ECG, QTc, Menstrual cycle, influence of estrogen.

\section{Introduction}

Women are at higher risk than men, of developing a dangerous drug-induced cardiac arrhythmia that can be fatal. This risk may be heightened during menstruation and ovulation'. Ventricular arrhythmias are more common in women and its incidence exhibits cyclical variation with the menstrual cycle ${ }^{2}$.

The menstrual cycle is a repetitive phenomenon

\footnotetext{
Corresponding Author:

Dr. Mudassir Mirza

Assistant Professor of Physiology, Osmainia Medical

College, Koti, Hyderabad-500095, T.S.

e-mail: mirza141@gmail.com

Contact No.: 9618085699
}

occurring during the reproductive life of a female that involves a patterned sequence of structural, functional and hormonal changes in the reproductive system ${ }^{3}$. It is also a window into the general health and well-being of women and not just are productive event. The cyclical fluctuations in the levels of FSH, LH, oestrogen and progesterone changes occurring during menstrual cycle not only affect oocyte maturation and the endometrial and vaginal environment but can also effect on the cardiovascular system which are of immense clinical significance ${ }^{4}$.

The electrocardiogram (ECG) is a useful noninvasive tool for the diagnosis and prognosis of a wide range of cardiovascular conditions. An Electrocardiogram consists of a $\mathrm{P}$ wave, a QRS complex and a $\mathrm{T}$ wave. TheQT interval is measured from the beginning of theQRS complex to the end of the $\mathrm{T}$ wave. Corrected 
QT (QTc) takes into account the physiologic shortening of the QT with increases in heart rate and has commonly been calculated using Bazett's formula $(\mathrm{QTc}=\mathrm{QT} /$ ORR) $)^{5}$.

The electrical events underlying the QT interval correspond with the phases of ventricular myocyte action potential (AP) generation at thecellular level. Specifically, the interval between the onset of the Q wave and the beginning of the $\mathrm{S}$ wave correspondsto the initial rapid upstroke of the AP (phase 0) and the early phase of repolarization (phase 1). The interval between the $\mathrm{S}$ wave and the peak of the $\mathrm{T}$ wave corresponds to theplateau phase of the AP (phase 2) and the peak of the Twaveto the end of the $T$ wave corresponds to the final repolarization phase (phase 3$)^{6}$.

During phase 2, the L-type calcium channel current (ICa, L) plays a dominant role ${ }^{7}$. Up regulation of $\mathrm{ICa}$, L channel currents lengthens the QT, whereas down regulation shortens the QT. During phase 3, the delayed rectifier potassium channel currents (consisting of the rapidly activating (IKr) and slowly activating (IKs) channel types) and the inward rectifier current (IK1) play a dominant role. ${ }^{8} \mathrm{Up}$ regulation of these channel currents shortens the QT, whereas down regulation lengthens the QT. Mechanistic studies suggest that testosterone, estrogen and progesterone have varying effects on the ICa, L, IKr, IKs and IK1 channel currents, providing a plausible mechanism for the QT alterations described in humans ${ }^{9-14}$.

Experimental data in animals show that it regulates there polarization phase of the cardiac action potential reflected by the QTinterval ${ }^{15}$. Estrogen decreases potassium channel current and may lengthen the QT interval through this mechanism ie., enhancement of IKs current in ventricular myocytes ${ }^{9}$. Saito et al. ${ }^{16}$ compared the QTc of mice with high endogenous estrogen to the QTc of ovariectomizedmice with no detectable endogenous estrogen. They found a significantly shorter QTc in the ovariectomized group $(\mathrm{p}<0.05)$. Further, when estradiol was added back to the ovariectomized group, the QTc lengthened to pre-surgical values, but these results could not be replicated in humans. Saba et., $\mathrm{al}^{17}$ compared 36 premenopausal women (mean age 36 years) to 65 postmenopausal women (mean age 72 years). They found no significant difference between the average QTc of premenopausal (405- 21 $\mathrm{msec})$ and postmenopausal $(419-30 \mathrm{msec})$ women $(p=N S)$ despite significantly lower estradiol levels in the postmenopausal group. Hence it could be deduced from animal studies that these hormones could affect Electrocardiographic pattern.

This hormonal variation during menstrual cycle is known to influence autonomic nervous system with increased sympathetic activity and reduced vagal tone during secretory phase of menstrual cycle which can cause heart rate variability during different phases of menstrual cycle ${ }^{21}$.

Among all phases of menstrual cycle estrogen is relatively high during proliferative phase. Burke et al. ${ }^{24}$ measured the Q-Tinterval among the different phases of menstrual cycle and found no statistical difference among the 3 phases of the menstrual cycle $(421+/-10$, $423+/-18$ and $420+/-18$ in the menstrual, proliferative and secretory phases, respectively).

So also J.S. Hulot et al. ${ }^{26}$ found that the mean QT interval was not different during various phases of menstrual cycle: $382.2 \pm 19.4 \mathrm{~ms}$ for Estrogen nadir period during menstrual phase versus $382.1 \pm 18.4 \mathrm{~ms}$ for Estrogen peak period $(\mathrm{P}=0.98)$ during proliferative phase.

In previous studies undertaken on ECG changes during menstrual cycle in humans were often contradictory and variable. So, the present study was undertaken tore-examine the findings in female of reproductive age group and thus provide a screening tool to avoid morbidity and mortality related to menstrual cycle.

Aims and Objectives: The present study was undertaken with the aim to investigate influence of hormonal fluctuation during menstrual cycle on ECG, with an objective to compare heart rate, QT interval and QTc interval in ECG changes during different phases of menstrual cycle.

\section{Materials and Method}

Source of Data: -30 Healthy female medical students aged between 18-23 years of medical students from Gandhi Medical College, Secunderabad were taken for the study.

Study Design: Cohort study

\section{Parameters:}

1. Age 
2. Height

3. Weight

4. Basal Body Temperature

5. Heart Rate

6. QT and QTc Interval

\section{Inclusion Criteria:}

i. $\quad 30$ healthy female medical students aged between 18-23 years were selected for the study.

ii. Normal regular menstrual cycles of 27-33 days.

\section{Exclusion Criteria:}

i. Subjects below 18 yrs and above 23 yrs of age.

ii. Subjects with endocrinal \& gynecological disorders, chronic diseases, cardiac disorders and allergic conditions.

iii. Presence of infection at the time of sampling.

iv. Subjects with Diabetes.

v. Pregnant subjects.

vi. Subjects with irregular menstrual cycle.

vii. H/O drugs intake affecting menstrual cycle/cardiac function

Method of collection of data: ECG of Female medical students were recorded at the Human physiology Laboratory in the Department of Physiology of Gandhi Medical College, Secunderabad. It was done after obtaining their informed consent and institutional ethical committee clearance.

\section{Anthropometric Variables:}

Weight was recorded by using standard weighing machine and height was measured by stadiometer. BMI was calculated. Body mass index (BMI): This was calculated as weight (in $\mathrm{Kg}$ ) divided by height in (meters $)^{2}$. BMI $=\mathrm{Wt}(\mathrm{Kg}) / \mathrm{ht}\left(\mathrm{m}^{2}\right)$.

Basal body temperature was recorded daily to confirm ovulation. Temperature was recorded daily with the help of digital thermometer in the early morning before getting out of bed.

Recording of ECG: The ECG was recorded using ADINSTRUMENT-POWERLAB $® / 30$ Series. Gel was applied to both wrist and right foot. Red Electrode (-veelectode) wasp laced over right wrist, black electrode (+veelectode) was placed over left wrist and the green electrode (earth) was placed over right foot. These Electrodes were connected to channel 1 of Bio Amp Cable.

The subjects were instructed to abstain from tea and caffeine like beverages for $2 \mathrm{hrs}$. Prior to the experiment, have adequate rest, get at least 8 hours of uninterrupted sleep on the night prior to the experiment, have a normal breakfast on the morning of the experiment and to void urine prior to the recording. ECG changes were recorded during the following phases of menstrual cycle: Menstrual phase ( $2^{\text {nd }}$ day), Proliferative phase ( $11^{\text {th }}$ day) and Secretory phase $\left(22^{\text {nd }}\right.$ day).

All recordings were conducted between 10:30 A.M. to 1:00 P.M. It was ensured that the temperature of the human physiology lab was comfortable before and after the E.C.G. recording. After comfortable strapping and rest for 5 minon the couch. Students were instructed tore move metallic ornaments or watch, they were asked not to move their limbs during recording. Recording was taken for 2 minand the ECG analysis was done. Heartrate, QTinterval were recorded. From these recording suitable sections were taken out leaving behind the time of onset.

Statistical analysis: Was done using SPSS17.0 Software. To compare means of two independent groups, students t- test for independent samples was used. The values were considered statistically significant if $\mathrm{P}-$ value $<0.05$

\section{Results}

30 female medical students were investigated during different phases of menstrual cycle namely Menstrual phase (MP), Proliferative phase (PP), Secretory phase (SP). 
Table 1: Anthropometric measurement and ECG changes

\begin{tabular}{|c|c|c|c|c|c|c|c|c|c|}
\hline Parameter & $\begin{array}{c}\text { MP } \\
(\text { Mean } \pm \text { S.D })\end{array}$ & PP $($ Mean \pm S.D & $\begin{array}{c}\text { SP } \\
(\text { Mean } \pm \text { S.D })\end{array}$ & \multicolumn{2}{|c|}{ MPVs PP } & \multicolumn{2}{|c|}{ MPVsSP } & \multicolumn{2}{|c|}{ PPVsSP } \\
\hline Age (yrs) & $18.53 \pm 0.73$ & $18.53 \pm 0.73$ & $18.53 \pm 0.73$ & & & & & & \\
\hline Height (m) & $1.57 \pm 0.063$ & $1.57 \pm 0.063$ & $1.57 \pm 0.063$ & & & & & & \\
\hline Weight (Kgs) & $53.73 \pm 9.49$ & $53.47 \pm 9.40$ & $53.63 \pm 9.44$ & 0.109 & $\mathrm{P}=0.95$ & 0.041 & $\mathrm{P}=0.99$ & 0.068 & $\mathrm{P}=0.95$ \\
\hline $\operatorname{BMI}\left(\mathrm{Kg} / \mathrm{m}^{2}\right)$ & $21.79 \pm 3.37$ & $21.89 \pm 4.52$ & $21.75 \pm 3.37$ & 0.097 & $\mathrm{P}=0.96$ & 0.136 & $\mathrm{P}=0.87$ & 0.046 & $\mathrm{P}=0.99$ \\
\hline Heart Rate (BPM) & $91.85 \pm 10.27$ & $93.10 \pm 8.58$ & $98.26 \pm 10.44$ & 2.04 & $\mathrm{P}=0.63$ & 2.04 & $\mathrm{P}=0.03 *$ & 2.04 & $\mathrm{P}=0.06$ \\
\hline QTinterval (m.sec) & $218.9 \pm 100.6$ & $249.92 \pm 59.9$ & $243.9 \pm 52.36$ & 0.426 & $\mathrm{P}=0.62$ & 0.584 & $\mathrm{P}=0.58$ & 0.977 & $\mathrm{P}=0.38$ \\
\hline QTc interval (m.sec) & $306.005 \pm 66.05$ & $317.97 \pm 71.77$ & $303.08 \pm 64.69$ & 2.045 & $\mathrm{P}=0.38$ & 1.699 & $\mathrm{P}=0.32$ & 2.045 & $\mathrm{P}=0.45$ \\
\hline
\end{tabular}

*P<0.05- BMI, Body Mass Index; MP, Menstrual Phase; PP, Proliferative Phase; SP, Secretory Phase

\section{Discussion}

This study was conducted in order to detect influence of phases of menstrual cycle on the duration of ventricular repolarization under physiological conditions and test the hypothesis that endogenous oestrogens prolong QT interval duration ${ }^{15,} 19$.

Age (years) i.e., height (meters) indifferent phases of menstrual cycle were (Mean \pm S.D) $18.53 \pm 0.73,1.57$ \pm 0.063 , respectively, where as Weight (Kgs), BMI (Kg/ $\left.\mathrm{m}^{2}\right)($ Mean \pm S.D) were $53.73 \pm 9.49,53.47 \pm 9.40$ and $53.63 \pm 9.44 ; 21.79 \pm 3.37,21.89 \pm 4.52$ and $21.75 \pm 3.37$. No statistically significant difference in weight and BMI were noted in different phases of menstrual cycle. This was consistent with study done by Haghighizadeh MH et al. ${ }^{20}$.

Other observation in the study was Heart Rate (BPM) in MP, PP, SPwere (91.85 \pm 10.27$),(93.10 \pm 8.58)$, (98.26 \pm 10.44$)$, respectively. It was significantly increased in SP compared to MP. $\mathrm{P}=0.03 *$ ie., $(\mathrm{P}<0.05)$. Similar findings of mean H.R. $79.08 \pm 8.84$ during menstrual phase and $86.31 \pm 7.98$ during secretory phase were reported by Brar T.K. et., al ${ }^{18}$. This phenomenon can be explained by increased sympathetic tone and reduced vagal tone balance during secretory phase of menstrual cycle ${ }^{21}$.

Oestradiol is implicated in decrease of the expression of potassium rectifier channels ${ }^{22,23}$ Therefore slowing there polarization phase of the cardiac action potential and prolonging the QT interval. To prove this phenomenon Saba et al. ${ }^{17}$ compared 36 premenopausal women (mean age 36 years) to 65 postmenopausal women (mean age 72 years). They found no significant difference between the average QTc of premenopausal $(405-21 \mathrm{msec})$ and postmenopausal $(419-30 \mathrm{msec})$ women $(\mathrm{p}=\mathrm{NS})$ despite significantly lower estradiol levels in the postmenopausal group. In the present study QT and QTcinterval (m.sec) in MP, PP, SPwere $(218.9 \pm 100.6),(249.92 \pm \quad 59.9),(243.9 \pm \quad 52.36)$ and $(306.005 \pm 66.05),(317.97 \pm 71.77)$ and $(303.08 \pm 64.69)$ respectively. They were increased in PP (in this phase estrogen is relatively high) compared toot her phases but statistical significant values were not noted when compared during different phases of menstrual cycle i.e. MPVs PP, MPVsSP, PPVsSP.So also in study done by Burke et al. ${ }^{24}$ no significant change was observed in the Q-Tinterval among the different phases of menstrual cycle. Similarly the maximum Q-Tinterval was found during proliferative phase whereas Q-Tinterval was shorter in the secretory versus the menstrual phase but not significant in other studies ${ }^{25-28}$.

\section{Conclusion}

In the present study "The study of variation in heart rate, QT, QTc intervals indifferent phases of menstrual cycle"heart rate was significantly increased and maximum QT interval was noted during proliferative phase, though statistically not significant. This does not warrant endogenous estrogen has no influence on prolongation of QTc interval, as during a single menstrualcycle, progesterone levels but not estrogen levels have the dominant effect on ventricular repolarization in women ${ }^{27}$.

Ethical clearance- Institutional ethical committee Gandhi medical college

Source of Funding: Self 


\section{Conflict of Interest: Nil}

\section{References}

1. Rodriguez I, Kilborn MJ, Liu XK, Pezzullo JC, Woosley RL. Drug-induced QT prolongation in women during the menstrual cycle.JAMA 2001;285:1322-6

2. Rosano, G.M.C et al., Cyclical variation in paroxysmal supraventricular tachycardia in women. The Lancet, Volume 347, Issue 9004, 786 - 788

3. Kim. Barret, Susan. Barman, Scott. Boitano, Heddwen. Brooks. Ganong's Review of Medical Physiology, Edn 26, Tata McGraw-Hill publishers; 2019;392.

4. Sioba'n D. Harlow, Oona M.R. Campbell. Epidemiology of menstrual disorders in developing countries: a systematic review, BJOG: an International Journal of Obstetrics and Gynaecology. January 2004; Vol.111, pp. 6-16

5. Rautaharju PM, Surawicz B, Gettes LS, et al. AHA/ACCF/HRS recommendations for the standardization and interpretation of the electrocardiogram: Part iv: The ST segment, T and $U$ waves and the QT interval: A scientific statement from the American Heart Association Electrocardiography and Arrhythmias Committee, Council on Clinical Cardiology; the American College of Cardiology Foundation; and the Heart Rhythm Society: Endorsed by the International Society for Computerized Electrocardiology. Circulation 2009; 119:e241-250

6. James AF, Choisy SC, Hancox JC. Recent advances in understanding sex differences in cardiac repolarization. Prog Biophys Mol Biol 2007;94:265-319

7. Linz KW, Meyer R. Control of L-type calcium current during the action potential of guinea-pig ventricular myocytes. Physiol 1998;513:425-442

8. Snyders DJ. Structure and function of cardiac potassium channels. Cardiovasc Res 1999; 42:377-390.

9. Berger F, Borchard U, Hafner D, Putz I, Weis TM. Effects of 17 beta-estradiol on action potentials and ionic currents in male rat ventricular myocytes. Naunyn-Schmiedeberg Arch Pharmacol 1997;356:788-796.

10. Kakusaka S, Asayama M, Kaihara A, et al. A receptor independent effect of estrone sulfate on the herg channel. J Pharmacol Sci 2009; 109:152156.

11. Liu XK, Katchman A, Whitfield $\mathrm{BH}$, et al. In vivo androgen treatment shortens the QT interval and increases the densities of inward and delayed rectifier potassium currents in orchiectomized male rabbits. Cardiovasc Res 2003; 57:28-36.

12. Nakamura H, Kurokawa J, Bai $C X$, et al. Progesterone regulates cardiac repolarization through a nongenomic pathway: An in vitro patch-clamp and computational modeling study. Circulation 2007;116:2913-2922

13. Tanabe S, Hata T, Hiraoka M. Effects of estrogen on action potential and membrane currents in guinea pig ventricular myocytes. Am J Physiol 1999;277:H826-833

14. Ebert SN, LiuXK, Woosley RL: Female gender as a risk factor ford rug-induced cardiacarrhythmias: evaluation of clinical and experimental evidence, JWomens Health. 1998;7:547-57

15. Rautaharju PM, Zhou SH, Wong $\mathrm{S}$ et al. Sex differences in the evolution of the electrocardiographic QT interval with age. Can J Cardiol 1992;8:690-5.

16. Saito T, Ciobotaru A, Bopassa JC, Toro L, Stefani $\mathrm{E}$, Eghbali M. Estrogen contributes to gender differences in mouse ventricular repolarization. Circulation Res 2009;105:343-352.

17. Saba S, Link MS, Homoud MK, Wang PJ, Estes NA 3rd. Effect of low estrogen states in healthy women on dispersion of ventricular repolarization. Am J Cardiol 2001;87: 354-356.

18. Brar TK, Singh KD, Kumar A. Effect of Different Phases of Menstrual Cycle on Heart Rate Variability (HRV). J Clin Diagn Res. 2015;9(10):CC01-CC4.

19. Stramba-Badiale M, Locati EH, Martinelli A et al. Gender and the relationship between ventricular repolarization and cardiac cycle length during 24-h Holter recordings. Eur Heart J 1997;18:1000-6

20. Haghighizadeh MH, Karandish M, Ghoreishi M, Soroor F, Shirani F; Body weight changes during the menstrual cycle among university students in Ahvaz, Iran.;Pak J Biol Sci. 2014 Jul;17(7):915-9.

21. Yildirir A, Kabakci G, Akgul E, Tokgozoglu L, Oto A (2002) Effects of menstrual cycle on cardiac autonomic innervation as assessed by heart rate variability. Ann Noninvasive Electrocardiol (1):60-63 
22. Drici MD, Burklow TR, Haridasse V et al. Sex hormones prolong the QT interval and down regulate potassium channel expression in the rabbit heart. Circulation 1996;94:1471-4

23. Ebert SN, Liu XK, Woosley RL. Female gender as a risk factor for drug-induced cardiac arrhythmias: evaluation of clinical and experimental evidence. J Womens Health. 1998;7:547-57

24. Burke JH, Ehlert FA, Kruse JT et al. Genderspecific differences in the QT interval and the effect of autonomic tone and menstrual cycle in healthy adults. Am J Cardiol 1997;79:178-81

25. Rajnee, Vinod Kumar Chawla, Raghuveer Choudhary, Bijendra Kumar Binawara,
Sunita Choudhary. Haemato logical and electrocardiographic variations during menstrual cycle. Pak JPhysiol. 2010;6(1):18-21.

26. HulotJS, Demolis JL, Riviere R, Strabach S, Maitre $\mathrm{S}$, Brentano C.Influence ofendogenousoestrogenson QT interval duration. Eur Heart J. 2003;24:1663-7

27. Nakagawa M, Ooie T, Takahashi N, et al. Influence of menstrual cycle on QT interval dynamics. PACE 2006;29: 607-613.)

28. Rodriguez I, Kilborn MJ, Liu XK, Pezzullo JC, Woosley RL. Drug-induced QT prolongation in women during the menstrual cycle. JAMA 2001; 285:1322-1326 